\title{
Arsenic speciation and kinetic release simulation of stream sediment contaminated by gold mining
}

\author{
Yongbing Cai ${ }^{1,2} \cdot{\text { Yuting } \mathrm{Mi}^{3} \cdot \text { Jing Yu }}^{1,2} \cdot$ Hua Zhang ${ }^{1}$
}

Received: 24 August 2015 / Accepted: 1 December 2015 /Published online: 15 December 2015

(C) Springer-Verlag Berlin Heidelberg 2015

\begin{abstract}
Purpose Understanding the mechanisms and kinetics controlling the release of metals from sediment is a prerequisite for evaluating the risk of sediment contaminated by toxic elements. The objectives of this research were to determine the leaching properties of arsenic (As) from stream sediment contaminated by gold mining and to quantify the kinetic rate of As release using a leaching experiment and numerical modeling.

Materials and methods In this study, we collected surface stream sediment from Jiehe River which was contaminated by gold mining in Zhaoyuan, Shandong Province. Chemical speciation of As was analyzed by a modified three-step BCR sequential extraction procedure. The sediment microscopic morphological characteristics and elemental composition on the surface of the sediment were analyzed by scanning electron microscope-energy dispersive spectrometer (SEM-EDS). Release kinetics of As were studied by a simulated leaching experiment using a stirred-flow reactor and a two-site equilibrium-kinetic model.

Results and discussion The sediments we studied were significantly contaminated by As, with maximum concentrations of $777.8-3389 \mathrm{mg} / \mathrm{kg}$. Sequential extraction analysis suggested
\end{abstract}

Responsible editor: Marcel van der Perk

Hua Zhang

hzhang@yic.ac.cn

1 Key Laboratory of Coastal Zone Environmental Processes and Ecological Remediation, Yantai Institute of Coastal Zone Research, Chinese Academy of Sciences, Yantai, Shandong, China

2 University of Chinese Academy of Sciences, Beijing, China

3 School of Environment and Materials Engineering, Yantai University, Yantai, Shandong, China that As contents in weak acid extractable, oxidizable, reducible, and residual forms were 2.6-9.8, 18-79, 2.4-7.1, and $8.7-75 \%$, respectively. SEM-EDS analysis showed that As on the surface of the sediment was higher than its overall content in all four sediments especially sediment JH27, which has high content of TOC, indicating that abundant As was sorbed or precipitated on the sediment surface. Our two-site equilibrium-kinetic model fits the As release data well and can reproduce the stop-flow experimental results. Kinetic rates obtained from curve fitting showed large variation among sediments for As, indicating different reaction mechanisms.

Conclusions The release of As from stream sediment contaminated by gold mining was nonequilibrium and timedependent and might cause long-term pollution to river water. Our two-site model was demonstrated as an effective tool to describe the kinetic release of As from stream sediment to waters.

Keywords Arsenic $\cdot$ Kinetic release $\cdot$ Gold mining . Speciation $\cdot$ Stream sediment

\section{Introduction}

Arsenic (As) is a ubiquitous toxic element which can be encountered in soils, sediments, and waters and widely distributed in natural ecosystems (Mandal and Suzuki 2002; Wang and Mulligan 2006). The presence of As at levels exceeding the maximum concentration limit (MCL) of $10 \mu \mathrm{g} / \mathrm{L}$ recommended for drinking water by the World Health Organization (WHO 1993) is now one of the major threats to human health in many areas of the world. Earlier studies have shown that ingestion of drinking water and food is the primary route of As exposure to humans (NRC 1999; Nriagu et al. 2007). It has been estimated that as many as $60-100$ million people 
globally may be at risk of exposure to excessive levels of As (Ng et al. 2003). With the rapid development of the mining and smelting industry, elevated concentrations of As in natural waters, soils, and sediments associated with mine water, beneficiation wastewater, and mine tailings (Paikaray 2015; Desbarats et al. 2015). Gaur et al. (2005) found that As discharged into the stream water can precipitate and accumulate onto stream sediment and eventually enter the food chain. Acting as sinks for contaminants, sediment plays an important role in maintaining water quality by removing contaminants from the water column. However, subsequent release of contaminants from the sediment can increase heavy metal in waters in excess of environmental standards even hundreds of years after the initial source has been removed (Linge 2008; Equeenuddin et al. 2013). Therefore, stream sediment acts not only as a sink of As but also as a potential secondary source of As in aquatic systems (Varol 2011). As can easily bound to sediment and cause its accumulation in stream sediment (Brannon and Patrick 1987), especially in mining areas. Earlier studies have found that concentration of As can reach up to hundreds or thousands of milligrams per kilogram in stream sediment of mining areas (Smedley and Kinniburgh 2002; Zhang et al. 2014). Therefore, it is important to understand the mechanisms controlling the release of As from stream sediment contaminated by mining, and it is a prerequisite for developing remediation strategies in the watersheds.

Once associated with soils or sediments, the primary process of metals release into liquid phase is leaching (Kim and Hyun 2015). However, not all elements present in sediment are equally susceptible to leaching upon interacting with water. Readily leachable or recalcitrant forms of elements vary largely and depend on the chemical forms of the elements in the sediment (Kwon and Lee 2001; Macgregor et al. 2015; Pandey et al. 2015). In addition, release of elements from contaminated sediment is effected by environmental conditions such as $\mathrm{pH}$, phosphate, redox conditions, and time (Rubinos et al. 2011; Molinari et al. 2014; Dang et al. 2014). Although there are many studies about As mobilization and release from soils or sediments in mining areas (Paikaray 2015; Macgregor et al. 2015; Desbarats et al. 2015), quantitative information regarding the leaching of As in stream sediment in mining areas, particularly under hydrodynamic conditions, is rare.

In our study, sequential extraction procedure (SEP) coupled with SEM-EDS was conducted on stream sediment to evaluate the solid phase speciation of As and elemental composition of sediment. A leaching experiment and a two-site equilibrium-kinetic reaction model were used to understand the leaching properties and release mechanisms of As. The main goal of this study is (1) to quantitatively determine the kinetic rate and extent of As release using a numerical model and (2) to provide basic parameters for further modeling efforts to better assess the risks of As release from contaminated sediment and thus potentially develop better remediation techniques.

\section{Materials and methods}

\subsection{Site description and sample select}

The Jiehe River is located in the northwest of Shandong peninsular with a latitude $37^{\circ} 05^{\prime} \mathrm{N}-37^{\circ} 33^{\prime} \mathrm{N}$ and a longitude $120^{\circ} 08^{\prime} \mathrm{E}-120^{\circ} 38^{\prime} \mathrm{E}$. There are three major tributaries, the Bujia River, Chengdong River, and Zhongliu River, contributing to the main stem of the Jiehe River as it flows northwest into the Laizhou Bay of Bohai Sea. Known as the "gold capital of China," Zhaoyuan has a long history of gold mining that can be traced back to 595 A.D. in Chinese Literature (Yang and Zhou 2000; Liang et al. 2011). Our earlier studies have demonstrated that with the rapid development of mining and smelting industry, abundance of heavy metals $(\mathrm{As}, \mathrm{Cr}, \mathrm{Cu}$, $\mathrm{Zn}, \mathrm{Cd}, \mathrm{Pb}$ ) was released into the Jiehe River and then enriched into sediment with the mine water and tailings (Zhang, et al. 2014).

In April 2014, we collected four sediments from the Jiehe River, which was heavily contaminated by As (see Fig. 1). Composite samples of surface $(0-5 \mathrm{~cm})$ sediment were grabbed from the bottom of stream channel and stored in sealed plastic bags. Stream sediment samples were air dried and passed a 2-mm sieve before chemical analysis. Two of the four sediments (LS12 and LS16) were collected in the upstream channel, and the other two sediments (JH26 and JH27) were collected in the midstream channel. All four sediments were heavily influenced by acid mine drainage (AMD).

\subsection{Physicochemical analysis}

Total organic carbon (TOC) was determined on dried sediment by dry combustion using an elemental analyzer (Vario MACRO cube, Elementar, Germany). Soil particle size was analyzed using a laser particle size analyzer (Marlvern Mastersizer 2000F, Malvern, UK). The sediment microscopic morphological characteristics and element composition on the surface of the sediment were analyzed by a scanning electron microscope-energy dispersive spectrometer (SEM-EDS) (S-4800, Hitachi, Japan). Soil pH (Metrohm 888 Titrando, Switzerland) was measured in a 1:10 soil-water suspension after stirring for $30 \mathrm{~min}$ ( $\mathrm{Lu} 2000$ ).

Sequential extraction methods have been used to examine As partitioning sediments, which contained different sequential extraction schemes that vary in number of steps, shaking times, extracting reagents, etc. (Keon et al. 2001; Wenzel et al. 2001; Van Herreweghe et al. 2003; Hudson-Edwards et al. 2004; Huang and Kretzschmar 2010). Despite the lack of 


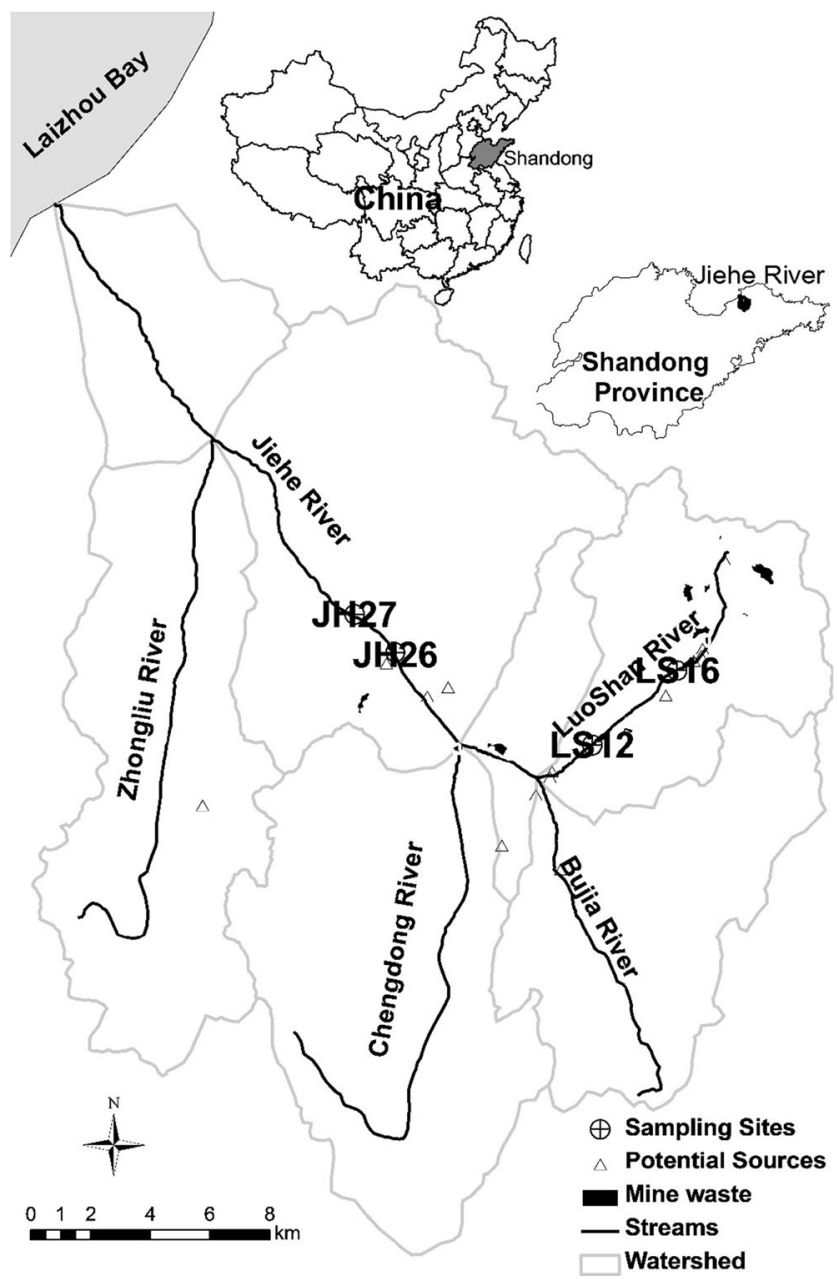

Fig. 1 Map showing location of sampling sites, four sediments we studied (LS12, LS16, JH26, JH27), and stream reaches in the Jiehe River watershed

standardized methods, sequential extraction methods can provide a broad-brush picture of As partitioning and, when combined with other techniques, can be useful for examining As mobility from solids (Hudson-Edwards et al. 2004). The three-step sequential extraction procedure proposed by the Commission of the European Communities Bureau of Reference (BCR) has been applied commonly for the fractionation of heavy metals (Table 1) and is utilized in our study (Rauret et al. 1999; Zemberyova et al. 2006; Pueyo et al. 2008). The total concentrations of iron, manganese, and trace metals were determined by inductively coupled plasma-mass spectrometry (ICP-MS, ELAN DRC II, PerkinElmer, USA) after digestion of sediment. About $0.10-\mathrm{g}$ sediment sample was digested with a 5:2:1 mixture of $\mathrm{HNO}_{3}-\mathrm{HClO}_{4}-\mathrm{HF}$ for $12 \mathrm{~h}$ at $180^{\circ} \mathrm{C}$. In the analysis of metals, certified standard reference materials (GSS-2, GSS-6, GSS-7, and GSS-8 geochemical reference materials) from the National Research Center for Certified Reference Materials of China were used in the digestion and analysis as part of the QA/QC protocol. Reagent blanks and analytical duplicates comprising $10 \%$ of the total samples were also used to test the accuracy and precision of the analysis. The standard deviation remained within $5 \%$ for all of the metals determined.

\subsection{Leaching experiment}

The leaching experiments were conducted by leaching sediment with $10 \mathrm{mM} \mathrm{Ca}\left(\mathrm{NO}_{3}\right)_{2}$ as the background electrolyte. A stirred-flow reactor, described in detail elsewhere (Yin et al. 1997), was used in our leaching experiment. A 1.0-g sediment sample was put in the $42-\mathrm{mL}$ reaction volume chamber ( $25 \mathrm{~mm}$ i.d.). The sealed chamber was fully filled with background electrolyte solution, and the suspension was stirred for 20 min without flow to hydrate the sediment (preequilibration). After preequilibration, the background electrolyte was pumped through the chamber at fixed flow rate $\left(2 \mathrm{~mL} \mathrm{~min}^{-1}\right)$ using a peristaltic pump (BT102S, Leadfluid, China). Variation of flow rate within each experiment did not exceed $5 \%$. To diminish diffusion (Sparks 1989), the sediment and solution were well mixed by a magnetic stirrer (H01-1B, ChiJiu, China) for the whole leaching process. Effluent was collected with a fraction collector (BS100A, BaiXian, China) using 5-min fixed time intervals for each sample. A $0.45-\mu \mathrm{m}$ filter paper was placed at the exit of the chamber. The leaching effluent samples were preserved at $4{ }^{\circ} \mathrm{C}$ before they were analyzed for As by ICP-MS. To determine whether metal release is kinetically controlled or instantaneous, a stop-flow was carried out by turning off the pumps for $30 \mathrm{~min}$ after leaching for $60 \mathrm{~min}$. The same flow interruption was repeated after leaching for an additional $150 \mathrm{~min}$.

\subsection{Equilibrium-kinetic reaction model}

Metal release from sediment particles is controlled by two reactions: desorption from sediment and sorption onto sediment. Sediment particles contain many different functional groups capable of binding metals. For simplification, we assume that a set of equilibrium sorption sites interacts instantaneously with background solution, whereas a set of reversible kinetic sites are time-dependent in nature. So, we established a two-site equilibrium-kinetic model to describe the release of As from sediment contaminated by heavy metals. We kept $\mathrm{Ca}$ concentration constant, so $\mathrm{Ca}$ competition for soil binding sites is not considered in our model. The model is described in the following formulations:

$S_{\mathrm{e}}=K_{d} C$

$\frac{\partial S_{k}}{\partial t}=k_{1} C-k_{2} S_{k}$

Here, $C$ is the concentration in solution, $S_{e}$ is the amount retained on equilibrium sites $\left(\mathrm{mg} \mathrm{g}^{-1}\right), S_{k}$ is the amount retained on kinetic sites $\left(\mathrm{mg} \mathrm{g}^{-1}\right), K_{d}$ is a dimensionless 
Table 1 Sequential extraction procedures used for this study

\begin{tabular}{|c|c|c|c|}
\hline $\begin{array}{l}\text { Extraction } \\
\text { steps }\end{array}$ & Speciation & Reagents used & Nominal target phases \\
\hline 1 & $\begin{array}{l}\text { Weak acid } \\
\text { extractable }\end{array}$ & $\begin{array}{l}0.11 \mathrm{~mol} \mathrm{~L}^{-1} \mathrm{CH}_{3} \mathrm{COOH}(20 \mathrm{~mL}) ; 24 \mathrm{~h} \\
\quad \text { at } 25^{\circ} \mathrm{C} \text { on shaker table }(200 \mathrm{rpm})\end{array}$ & $\begin{array}{l}\text { Carbonates, exchangeable } \\
\text { metals }\end{array}$ \\
\hline 2 & Reducible & $\begin{array}{l}0.5 \mathrm{~mol} \mathrm{~L}^{-1} \mathrm{NH}_{2} \mathrm{OH} \mathrm{HCl}(20 \mathrm{~mL}) ; 24 \mathrm{~h} \\
\quad \text { at } 25^{\circ} \mathrm{C} \text { on shaker table }(200 \mathrm{rpm})\end{array}$ & $\begin{array}{l}\text { Iron-manganese } \\
\text { oxyhydroxides }\end{array}$ \\
\hline 3 & Oxidizable & $\begin{array}{l}30 \% \mathrm{H}_{2} \mathrm{O}_{2}(10 \mathrm{~mL}) 1 \mathrm{~h} \text { at } 85{ }^{\circ} \mathrm{C} ; 1 \mathrm{~mol} \mathrm{~L}^{-1} \\
\mathrm{CH}_{3} \mathrm{COONH}_{4}(25 \mathrm{~mL}), \mathrm{pH} 2 ; 24 \mathrm{~h} \text { at } 25^{\circ} \mathrm{C} \\
\text { on shaker table }(200 \mathrm{rpm})\end{array}$ & Organic matter and sulfides \\
\hline 4 & Residual & Aqua regia & $\begin{array}{l}\text { Residues in the mineral } \\
\text { crystal lattice }\end{array}$ \\
\hline
\end{tabular}

Dried sediment $(1.0 \mathrm{~g})$ was extracted using the steps below. Steps 1-3 were washed with deionized water; the wash solution for each step was analyzed for arsenic equilibrium constant $\left(\mathrm{L} \mathrm{g}^{-1}\right)$, and $t$ is the reaction time (h). $k_{1}$ and $k_{2}$ are the forward (adsorption) $\left(\mathrm{L} \mathrm{g}^{-1} \mathrm{~min}^{-1}\right)$ and backward (desorption) $\left(\mathrm{min}^{-1}\right)$ reaction rate associated with kinetic sites, respectively. The total amount of solute retention on sediment is the following:

$S=S_{e}+S_{k}$

To simulate the release of As from sediment, the two-site equilibrium-kinetic formulations are incorporated into the steady state convection-dispersion equation (CDE) in the form of (Selim et al. 1989)

$\frac{\partial C}{\partial \mathrm{t}}=\frac{\partial}{\partial x}\left(D \frac{\partial C}{\partial x}\right)-v \frac{\partial C}{\partial x}-\frac{\partial S}{\partial t}$

where $x$ is the distance $(\mathrm{cm}), D$ is the hydrodynamic dispersion coefficient $\left(\mathrm{cm}^{2} \mathrm{~min}^{-1}\right)$, and $v$ is the flow rate $\left(\mathrm{cm} \min ^{-1}\right)$.

Statistical criteria used for estimating the goodness-of-fit of the models to the data were the coefficients of determination $\left(r^{2}\right)$ and the root mean square error (RMSE):

$R M S E=\sqrt{\frac{\sum\left(C_{o b s}-C_{\mathrm{mod}}\right)^{2}}{n_{o b s}-n_{p a r}}}$

where $C_{o b s}$ is the observed As concentration at certain time $t, C_{m o d}$ is the simulated As concentration at time $t$, $n_{o b s}$ is the number of measurements, and $n_{\text {par }}$ is the number of fitted parameters.

\section{Results and discussion}

\subsection{Sediment characteristics}

Table 2 shows that the four sediments have different properties. The samples collected from upstream (LS12 and LS16) have lower $\mathrm{pH}$ than samples from downstream (JH26 and $\mathrm{JH} 27$ ). This can be explained by the influence of acid mine drainage (AMD), which is formed by the decomposition of pyrites (Wolkersdorfer 2008). Oxidative dissolution of sulfide minerals such as pyrite causes water acidification and releases a large number of various toxic trace elements in the process (Abraitis et al. 2004; Chandra and Gerson 2010; Deditius et al. 2011). Sample JH27 has especially high TOC compared to the other three sediments because the sampling sites receive wastewater with high concentration of organic materials from a factory of vermicelli production. Total Fe in LS12 and LS16 was higher than $\mathrm{JH} 26$ and $\mathrm{JH} 27$, while on the contrary, total Mn in LS12 and LS16 was lower than $\mathrm{JH} 26$ and JH27. Higher content of Fe may be due to the high content of primary minerals in the upstream sediment influenced by mining waste. The lower $\mathrm{Mn}$ in the upstream sediment samples (LS12, LS16) may be due to the low $\mathrm{pH}$ conditions, which would prevent formation
Table 2 Basic physical and chemical properties of sediment

\begin{tabular}{llllllll}
\hline Sediment & $\mathrm{pH}$ & $\begin{array}{l}\text { TOC } \\
\left(\mathrm{g} \mathrm{kg}^{-1}\right)\end{array}$ & $\begin{array}{l}\text { Total Fe } \\
\left(\mathrm{g} \mathrm{kg}^{-1}\right)\end{array}$ & $\begin{array}{l}\text { Total Mn } \\
\left(\mathrm{g} \mathrm{kg}^{-1}\right)\end{array}$ & $\begin{array}{l}\text { Clay }^{\mathrm{a}} \\
(\%)\end{array}$ & $\begin{array}{l}\text { Silt } \\
(\%)\end{array}$ & $\begin{array}{l}\text { Sand } \\
(\%)\end{array}$ \\
\hline LS12 & 5.58 & 38.13 & 35.41 & 0.25 & 8.41 & 49.28 & 42.28 \\
LS16 & 4.21 & 17.74 & 73.99 & 0.23 & 6.90 & 40.94 & 52.17 \\
JH26 & 6.66 & 11.76 & 28.57 & 0.35 & 1.74 & 12.23 & 86.03 \\
JH27 & 7.84 & 116.69 & 31.70 & 0.44 & 5.46 & 34.00 & 60.54 \\
\hline
\end{tabular}

TOC total organic carbon

${ }^{\mathrm{a}}$ Grain size distribution: clay $(<2 \mu \mathrm{m})$, silt $(2-20 \mu \mathrm{m})$, and sand $(20-2000 \mu \mathrm{m})$ 
Fig. 2 SEM pictures of the four sediments
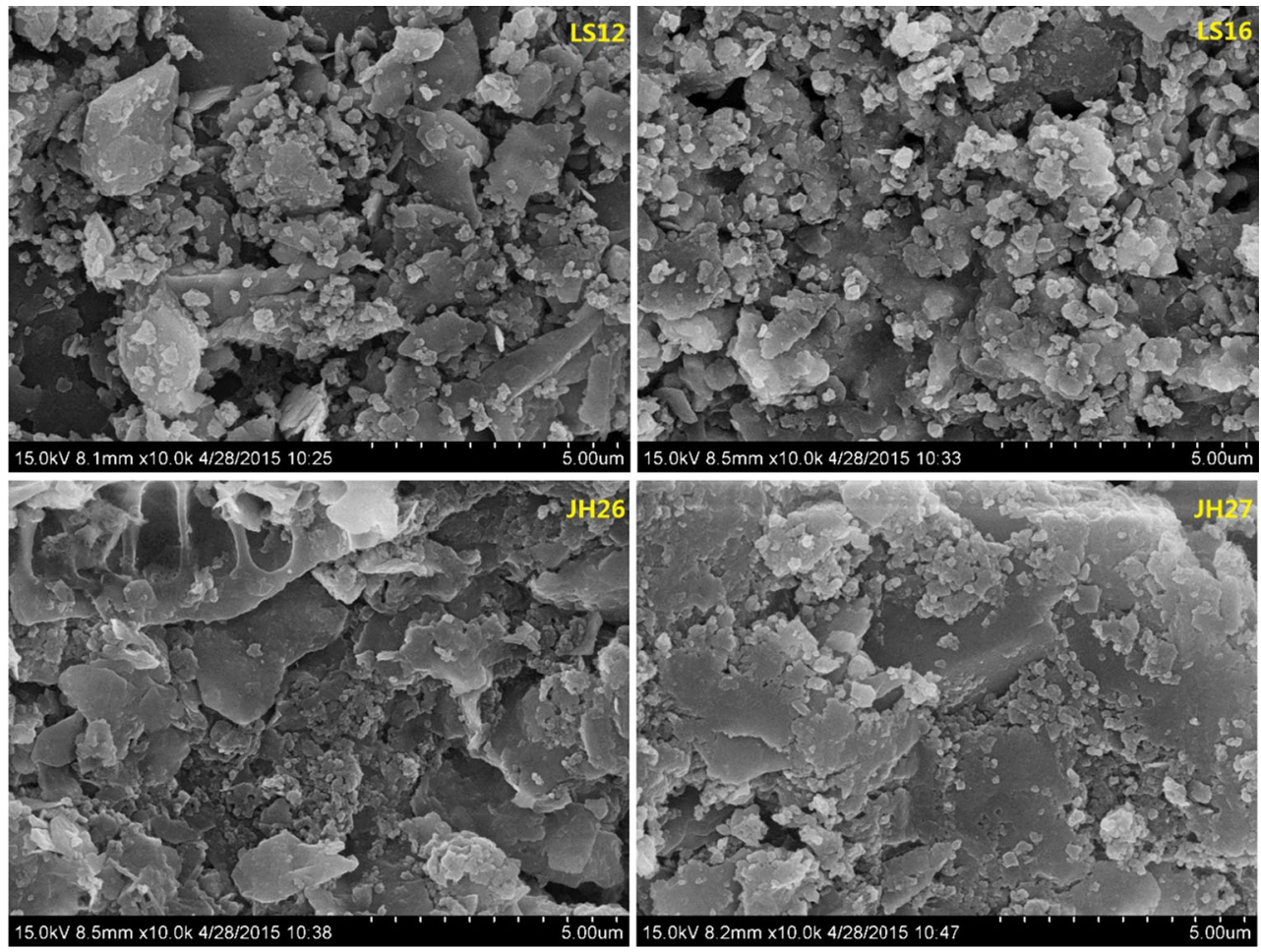

of Mn oxides and can cause Mn release and transport to downstream. LS12 and LS16 have similar size composition because of high content of tailing in the form of silt in the sediment of upstream. In sediment JH26 and JH27, sand is the major composition. SEM results showed that there was no significant difference between the four pictures (Fig. 2) of the sediments. But, the particle size of LS12 and LS16 was smaller than JH26 and $\mathrm{JH} 27$ which was consistent with our analysis using a laser particle size analyzer (Table 2).

Elemental composition (weight percentage, wt $\%$ ) on the surface of the sediment analyzed by SEM-EDS is shown in Table 3 . The content of carbon (C) on the surface of sediment LS12, LS16, JH26, and JH27 was 15.92, 10.41, 9.29, and $17.84 \%$, respectively. The content of $\mathrm{Fe}$ on the surface of the four sediments did not appear to be much different from each other. Except for LS16, Fe on the surface of the other three sediments is higher than their concentration of total Fe (Table 2). The concentration of As on the surface of the sediment was higher than its content in all the four sediments especially in sediment JH27 which has high content of TOC. The results showed that abundance of As was sorbed or precipitated on the sediment surface.

\subsection{Arsenic speciation in sediment}

The recovery of the sequential extraction procedure for the four sediments LS12, LS16, JH26, and $\mathrm{JH} 27$ is 98, 100, 109 , and $99 \%$, respectively, which means that the modified BCR extraction experiment that we used is an effective and reasonable method to analyze solid phase speciation of As in stream sediment. Concentration and fraction of As in the stream sediment are illustrated in Fig. 3. There were high concentrations of total As in sediment samples LS12 $\left(777.8 \mathrm{mg} \mathrm{kg}^{-1}\right), \operatorname{LS} 16\left(2,339 \mathrm{mg} \mathrm{kg}^{-1}\right), \mathrm{JH} 26$ $\left(1,426 \mathrm{mg} \mathrm{kg}^{-1}\right)$, and JH27 (3,389 $\left.\mathrm{mg} \mathrm{kg}^{-1}\right)$ (Fig. 3a).

The sequential extraction results showed that As content is associated with different solid-phase fractions (Fig. 3b). The contents of weak acid extractable form and oxidizable form are lower than those of the other two forms. Weak acid

Table 3 Element composition (weight percentage wt $\%$ ) on the surface of the sediment

\begin{tabular}{lrlllllllllllllll}
\hline Sediment & \multicolumn{1}{l}{$\mathrm{C}$} & $\mathrm{O}$ & $\mathrm{Na}$ & $\mathrm{Mg}$ & $\mathrm{Al}$ & $\mathrm{Si}$ & $\mathrm{P}$ & $\mathrm{S}$ & $\mathrm{Cl}$ & $\mathrm{K}$ & $\mathrm{Ca}$ & $\mathrm{Ti}$ & $\mathrm{Fe}$ & $\mathrm{Cu}$ & $\mathrm{Zn}$ & $\mathrm{As}$ \\
\hline LS12 & 15.92 & 48.17 & 0.38 & 0.59 & 11.66 & 8.97 & 1.55 & 4.83 & - & 0.80 & 0.75 & - & 4.51 & 1.46 & - & 0.39 \\
LS16 & 10.41 & 55.88 & 0.53 & 0.51 & 8.48 & 12.07 & 0.15 & 1.10 & - & 3.24 & - & 1.43 & 5.67 & - & - & 0.53 \\
JH26 & 9.29 & 47.77 & 1.36 & 0.52 & 10.82 & 17.29 & 0.66 & 0.76 & - & 1.97 & 3.12 & 0.25 & 4.81 & - & 0.94 & 0.44 \\
JH27 & 17.84 & 44.83 & 2.15 & 0.56 & 6.73 & 10.87 & 2.90 & 1.50 & 0.99 & 1.63 & 3.09 & - & 5.32 & - & 0.50 & 1.10 \\
\hline
\end{tabular}


Fig. 3 Arsenic concentration and fraction in the stream sediment. a Arsenic concentration in sediment LS12, LS16, JH26, and JH27. b Speciation of arsenic in the four stream sediment. Different patterns illustrate arsenic distribution in the following phases (from bottom to top): weak acid extractable form, reducible form, oxidizable form, and residual form
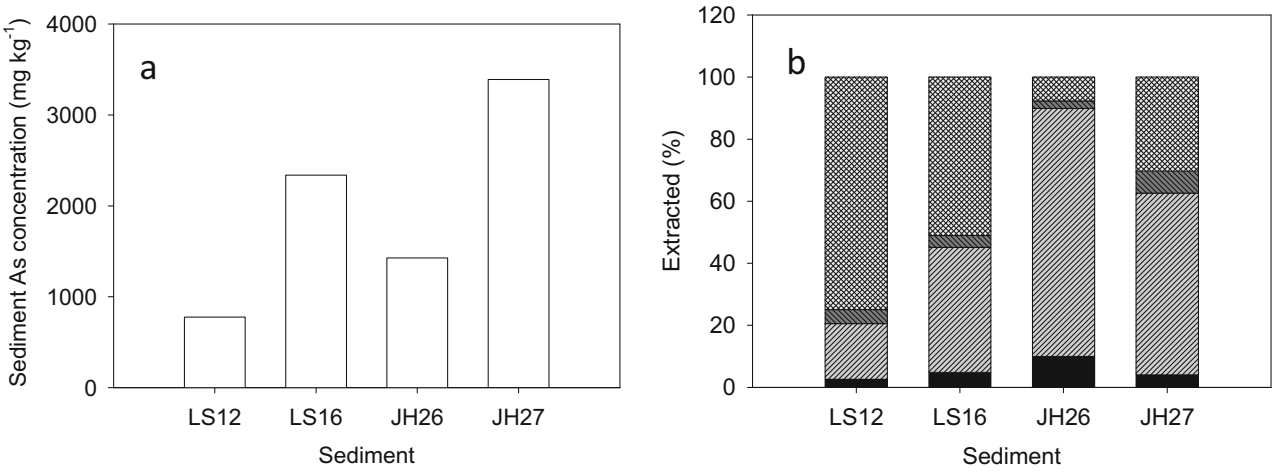

extractable forms include carbonates and water exchangeable forms, which can be easily released and cause risks to organisms directly. In sediment LS12 and LS16, As mainly exist in residual forms, but in sediment $\mathrm{JH} 26$ and $\mathrm{JH} 27$, As mainly associates with iron-manganese oxide. This indicates that most As present in the forms of primary minerals in upstream sediment can hardly be extracted because of its strong bound in the mineral crystal lattice, which suggests that the sources of As in the upstream sediments were tailing materials from gold mines. At downstream, the dominate from of As is associated with iron-manganese oxides, which indicate that As might be accumulated in the sediment as a result of continuous As loading from upstream water. Earlier studies often show that iron and manganese oxide have high affinity toward inorganic arsenic species (Zhang et al. 2007). Therefore, As can easily adsorb onto iron- manganese oxide surface in the process of transport to downstream and then may be released with the variation of environmental conditions, causing secondary pollution to streams.

Heavy metals of residual form in sediment are very stable and mostly in primary minerals and secondary silicate minerals lattice. They almost do not participate in sediment-water interactions and have lower mobility and bioavailability and cannot cause pollution in the short term (Teasdale et al. 2003). Extractable heavy metals (weak acid extractable, reducible, oxidizable) are not stable, and they can easily release from sediment and cause secondary pollution with environmental conditions changing. Since contaminated sediment would release heavy metals continuously and cause long-term pollution to river water, it is important to clarify the release mechanisms of heavy metals for choosing better remediation techniques.
Fig. 4 Kinetics of arsenic release from stream sediment, the white cycles depict the effluent arsenic concentration observed, solid line depicts the equilibrium-kinetic model simulations using parameters obtain from nonlinear optimization, and the dash line indicates two times of stop-flow (the flow stop and restart time are indicated in the experimental section)
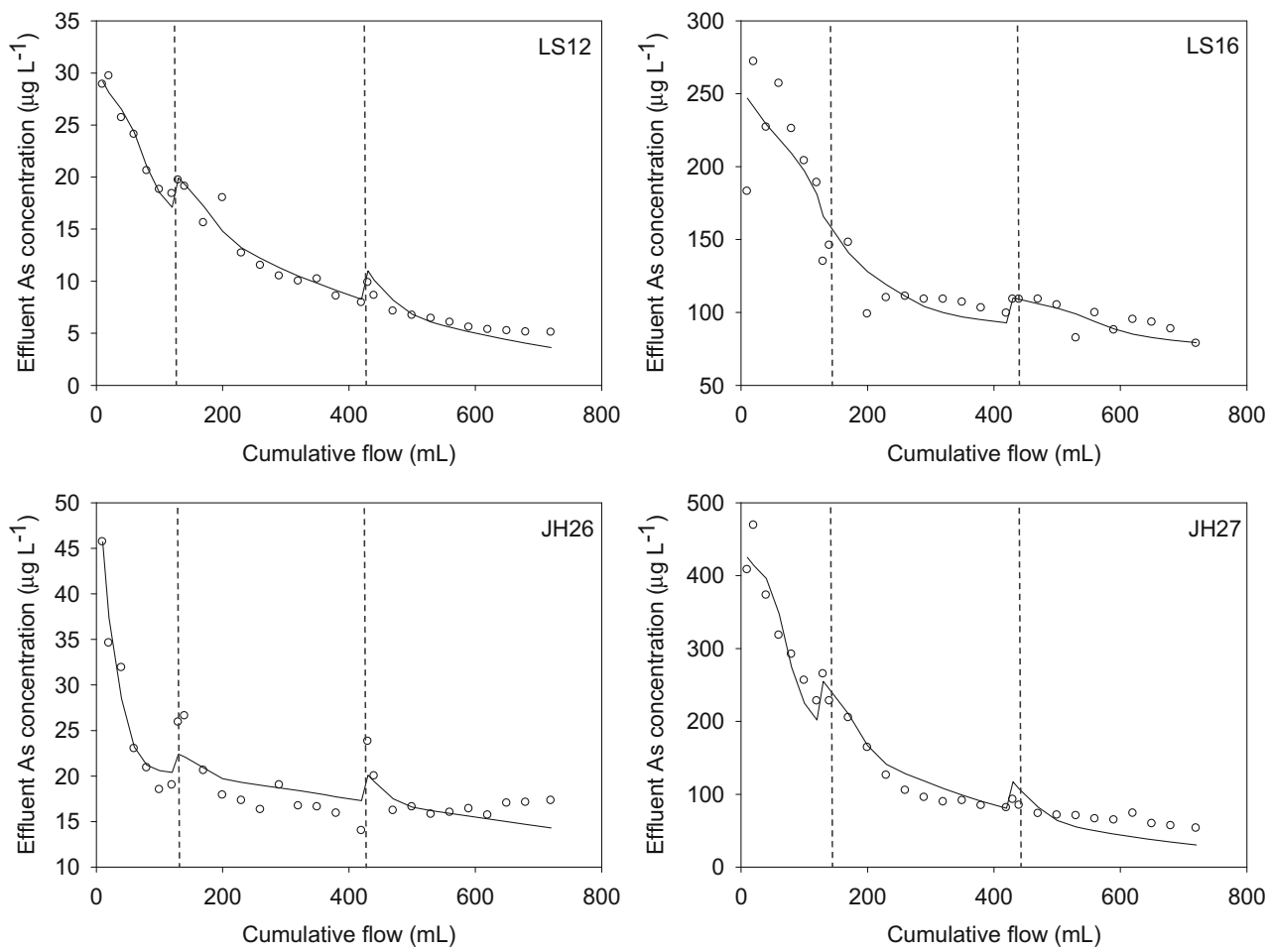
Table 4 Model fitting parameters for Arsenic release kinetics using an equilibrium-kinetic model

\begin{tabular}{llrlll}
\hline Sediment & $r^{2}$ & RMSE & $K_{d}\left(\mathrm{~L} \mathrm{~g} \mathrm{~g}^{-1}\right)$ & $k_{1}\left(\mathrm{~L} \mathrm{~g}^{-1} \mathrm{~min}^{-1}\right)$ & $k_{2}\left(\mathrm{~min}^{-1}\right)$ \\
\hline LS12 & 0.995 & 1.09 & $0.041 \pm 0.005$ & $0.038 \pm 0.006$ & $0.010 \pm 0.001$ \\
LS16 & 0.984 & 19.99 & $0.125 \pm 0.034$ & $0.014 \pm 0.003$ & $0.002 \pm 0.001$ \\
JH26 & 0.990 & 2.27 & $0.022 \pm 0.013$ & $0.088 \pm 0.016$ & $0.004 \pm 0.001$ \\
JH27 & 0.988 & 23.12 & $0.034 \pm 0.005$ & $0.027 \pm 0.005$ & $0.009 \pm 0.001$ \\
\hline
\end{tabular}

\subsection{Modeling As release kinetics}

The time-dependent release process of As was illustrated at the same flow rates $\left(2 \mathrm{ml} \mathrm{min}^{-1}\right)$ by the four stream sediments (Fig. 4). As was demonstrated as a mobile element with averaged concentration of $13,135,21$, and $161 \mu \mathrm{g} \mathrm{L}^{-1}$ in the leachate for sediments LS12, LS16, JH26, and JH27, respectively. Though the peak concentration of the leachate for the four sediments is different (LS12 $29.7 \mu \mathrm{g} \mathrm{L}^{-1}$, LS16 $271.5 \mu \mathrm{g} \mathrm{L}^{-1}$, JH26 $45.7 \mu \mathrm{g} \mathrm{L}^{-1}$, and JH27 $468.5 \mu \mathrm{g} \mathrm{L}^{-1}$ ), the release of As was consistent with their total concentration in sediments. The concentration of As released decreasing with the influent of background solution and gradually into balance. This trend is consistent with the release of other metals ( $\mathrm{Zn}$ and $\mathrm{Cu}$ ) (Shi et al. 2005).

Two stop-flow for $30 \mathrm{~min}$ was carried out at the cumulative flow 120 and $420 \mathrm{~mL}$, respectively. The concentration of As in the leachate increased after stop-flow for almost all four sediments except LS16 at cumulative flow of $120 \mathrm{~mL}$. The increase of As concentration after stop-flow demonstrates that release of As is a time-dependent process. The nonequilibrium leaching is likely due to transformation between recalcitrant and leachable forms (Kim and Hyun 2015).

Our experiment also revealed that the kinetic rate of As release can vary in a wide range depending on stream sediment characteristics (Table 4). Sediment sample LS16 showed higher $K_{d}$ value and smaller $k_{1}$ and $k_{2}$ values than the other three sediments, meaning that As release from sediment LS16 is mainly controlled by equilibrium sites. This could explain why As concentration in effluent of sediment LS16 did not increase like the other three sediments after the first stop-flow (Fig. 4). Sediments LS12 and JH27 showed that higher $k_{2}$ values indicated that the desorption of As from these two sediments was easily than sediment JH26. So, the timedependent release behavior of As has to be considered in modeling the fate and transport of As in stream sediment.

Figure 4 shows that our two-site equilibrium-kinetic model fit to the As release data can well reproduce the stop-flow experimental results. This demonstrates that this type of experiment is essential for estimating the kinetic model parameters (Bartal et al. 1990). Kinetic rate obtained from curve fitting (Table 4) showed large variation among sediments for As, indicating different reaction mechanisms. The rapid release stage of As was controlled by the combined action of equilibrium sites and kinetic sites, while the long-time release was controlled by the kinetic sites. Overall, this two-site model was demonstrated as an effective tool to describe the kinetic release of As from stream sediments to waters. Further studies will be conducted to evaluate the influences of environment variables including flow rates, $\mathrm{pH}$, and $\mathrm{DOM}$ on the kinetics processes of As in the field to better assess the risks of sediment release and choose appropriate remediation techniques.

\subsection{Amount of As release}

Figure 5a illustrates the amount of As released as calculated from experiment observation and equilibrium-kinetic model simulation. The calculated total amounts of released As in LS12 (8.3 mg kg$\left.{ }^{-1}\right)$, LS16 (89.1 $\left.\mathrm{mg} \mathrm{kg}^{-1}\right)$, JH26 (13.5 mg kg ${ }^{-1}$ ), and JH27 (96.7 $\mathrm{mg} \mathrm{kg}^{-1}$ ) are compared to the total content and extractable forms of As in sediment samples and shown in Fig. 5b. High amount of As was released from the sediments, especially from sediment LS16 and JH27. Furthermore, the close correlation between results of
Fig. 5 The leaching amount and leaching rate of arsenic. a Amount of arsenic release includes of observed (black pattern) and simulated (white pattern). b Percentage of arsenic released to total amount (black pattern) and to weak acid extractable form (white pattern)
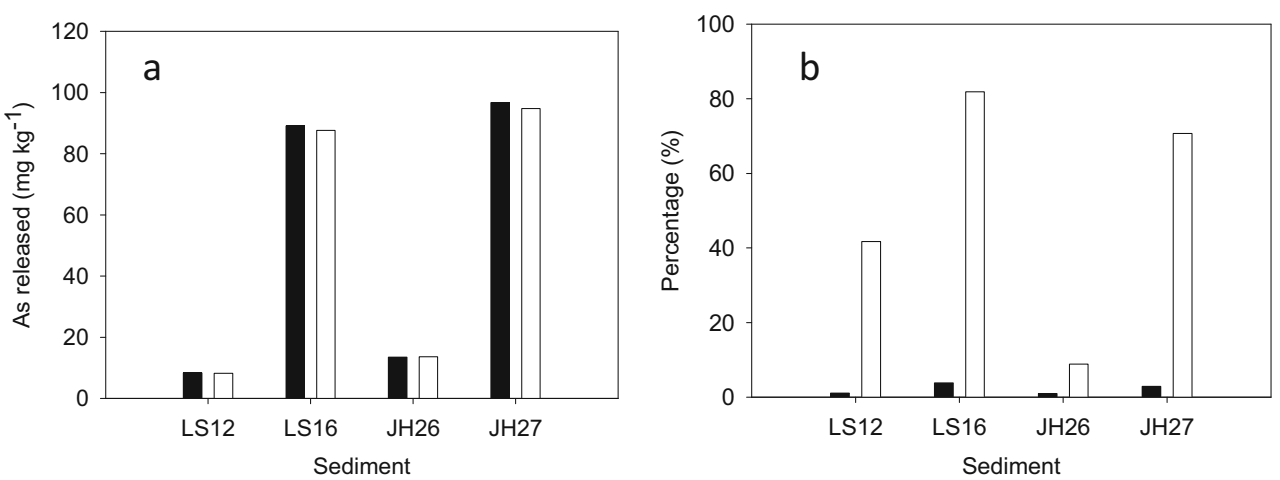
observation and simulation demonstrated that our two-site model could simulate the release of As well. Generally, the amount of As released constituted only a small portion of the total As in sediments and did not correlate with the total amount of As in the sediments. It shows that release of As from sediment was not only controlled by total content but also impacted by its chemical speciation in solid phases. The percentages of As released to weak acid extractable form were 41.7, 81.9, 8.9, and $70.7 \%$ for sediments LS12, LS16, JH26, and JH27, respectively (Fig. 5b). Extractable form of As has higher mobility than the other speciation and should be the major contributor to As release in our leaching experiment. A large fraction of As in weak acid extractable form of sediment LS16 and JH27 was released, while only small percentage of extractable As in sediment LS12 and JH26 was leached into solution. This might be because the weak acid extractable form of metals is a combination of water exchangeable and carbonate forms and only water exchangeable form can be released in our experiment system.

\section{Conclusions}

This study investigated the speciation and release kinetics of As in stream sediment contaminated by gold mining. The results showed that large fraction of As exists in primary mineral in upstream sediment and As can transport to downstream and transform to sorbed species associated with iron-manganese oxides in downstream sediment. As was demonstrated as a mobile element with averaged concentrations of 13, 135, 21, and $161 \mu \mathrm{g} \mathrm{L}^{-1}$ in the leachate for sediments LS12, LS16, $\mathrm{JH} 26$, and JH27, respectively. Our two-site equilibrium-kinetic model fits the release data of As well and can reproduce the stop-flow experimental results. Kinetic rate obtained from curve fitting showed large variation among sediments for As, indicating different reaction mechanisms. Total amount of As released (LS12 $8.3 \mathrm{mg} \mathrm{kg}^{-1}$, LS16 $89.1 \mathrm{mg} \mathrm{kg}^{-1}$, JH26 $13.5 \mathrm{mg} \mathrm{kg}^{-1}$, JH27 $96.7 \mathrm{mg} \mathrm{kg}^{-1}$ ) showed that large amount of As in sediment can be leached into solution and cause secondary contamination. Furthermore, our two-site model was demonstrated as an effective tool to describe the kinetic release of As from sediments to waters and can be further extended to predict trace metals release at contaminated sites with varying solution chemistry and sediment properties. Overall, the evaluation of environmental risk associated with contaminated stream sediment should consider the chemical speciation and kinetic processes of toxic elements at solid-water interfaces.

Acknowledgments The authors would like to thank Dr. Chengli Qu for chemical analysis. This work was financially supported by the National Natural Science Foundation of China $(41271506,41230858)$ and Key Research Program of the Chinese Academy of Sciences (KZZD-EW14). Dr. Hua Zhang was financially supported by the Recruitment Program of Global Young Experts (1000Plan).

\section{References}

Abraitis PK, Pattrick RAD, Vaughan DJ (2004) Variations in the compositional, textural and electrical properties of natural pyrite: a review. Int J Miner Process 74:41-59

Bartal A, Sparks DL, Pesek JD, Feigenbaum S (1990) Analyses of adsorption-kinetics using a stirred-flow chamber. 1 . Theory and critical tests. Soil Sci Soc Am J 54:1273-1278

Brannon JM, Patrick WH Jr (1987) Fixation, transformation, and mobilization of arsenic in sediments. Environ Sci Technol 21:450-459

Chandra AP, Gerson AR (2010) The mechanisms of pyrite oxidation and leaching: a fundamental perspective. Surf Sci Rep 65:293-315

Dang DH, Tessier E, Lenoble V, Durrieu G, Omanović D, Mullot J-U, Pfeifer H-R, Mounier S, Garnier C (2014) Key parameters controlling arsenic dynamics in coastal sediments: an analytical and modeling approach. Mar Chem 161:34-46

Deditius AP, Utsunomiya S, Reich M, Kesler SE, Ewing RC, Hough R, Walshe J (2011) Trace metal nanoparticles in pyrite. Ore Geol Rev 42:32-46

Desbarats AJ, Parsons MB, Percival JB (2015) Arsenic mobility in mildly alkaline drainage from an orogenic lode gold deposit, Bralorne mine, British Columbia. Appl Geochem 57:45-54

Equeenuddin SM, Tripathy S, Sahoo PK, Panigrahi MK (2013) Metal behavior in sediment associated with acid mine drainage stream: role of pH. J Geochem Explor 124:230-237

Gaur VK, Gupta SK, Pandey SD, Gopal K, Misra V (2005) Distribution of heavy metals in sediment and water of River Gomti. Environ Monit Assess 102:419-433

Huang JH, Kretzschmar R (2010) Sequential extraction method for speciation of arsenate and arsenite in mineral soils. Anal Chem 82: 5534-5540

Hudson-Edwards KA, Houghton SL, Osborn A (2004) Extraction and analysis of arsenic in soils and sediments. Trends Anal Chem 23: $745-752$

Keon NE, Swartz CH, Brabander DJ (2001) Validation of an arsenic sequential extraction method for evaluating mobility in sediments. Environ Sci Technol 35:2778-2784

Kim J, Hyun S (2015) Nonequilibrium leaching behavior of metallic elements $(\mathrm{Cu}, \mathrm{Zn}, \mathrm{As}, \mathrm{Cd}$, and $\mathrm{Pb})$ from soils collected from longterm abandoned mine sites. Chemosphere 134:150-158

Kwon Y-T, Lee C-W (2001) Ecological risk assessment of sediment in wastewater discharging area by means of metal speciation. Microchem J 70:255-264

Liang N, Yang LY, Dai JR, Pang XG (2011) Heavy metal pollution in surface water of Linglong gold mining area, China, 2011 3rd international conference on environmental science and information application technology esiat. Pt A, Procedia Environ Sci Elsevier Science Bv, Amsterdam 10:914-917

Linge KH (2008) Methods for investigating trace element binding in sediments. Crit Rev Environ Sci Technol 38:165-196

Lu RK (2000) Analytical methods for soil and agro-chemistry. China Agricultural Science and Technology Press, Beijing (in Chinese)

Macgregor K, MacKinnon G, Farmer JG, Graham MC (2015) Mobility of antimony, arsenic and lead at a former antimony mine, Glendinning, Scotland. Sci Total Environ 529:213-222

Mandal B, Suzuki K (2002) Arsenic round the world: a review. Talanta 58:201-235

Molinari A, Ayora C, Marcaccio M, Guadagnini L, Sanchez-Vila X, Guadagnini A (2014) Geochemical modeling of arsenic release from a deep natural solid matrix under alternated redox conditions. Environ Sci Pollut 21:1628-1637

Ng JC, Wang J, Sharim A (2003) A global health problem caused by arsenic from natural sources. Chemosphere 52:1353-1359

NRC (1999) Arsenic in drinking water. National Academic Press, Washington 
Nriagu JO, Bhattacharya P, Mukherjee AB, Bundschuh J, Zevenhoven R, Loeppert RH (2007) Arsenic in soil and groundwater: an overview. In: Bhattacharya P, Mukherjee AB, Bundschuh J, Zevenhoven R, Loeppert RH (eds) Arsenic in soil and groundwater environment: biogeochemical interactions, health effects and remediation. Elsevier, Amsterdam, pp 3-60

Paikaray S (2015) Arsenic geochemistry of acid mine drainage. Mine Water Environ 34:181-196

Pandey M, Pandey AK, Mishra A, Tripathi BD (2015) Assessment of metal species in river Ganga sediment at Varanasi, India using sequential extraction procedure and SEM-EDS. Chemosphere 134: 466-474

Pueyo M, Mateu J, Rigol A, Vidal M, López-Sánchez JF, Rauret G (2008) Use of the modified BCR three-step sequential extraction procedure for the study of trace element dynamics in contaminated soils. Environ Pollut 152:330-341

Rauret G, López-Sánchez JF, Sahuquillo A, Rubio R, Davidson C, Ure A, Quevauviller P (1999) Improvement of the BCR three step sequential extraction procedure prior to the certification of new sediment and soil reference materials. J Environ Monit 1:57-61

Rubinos DA, Iglesias L, Diaz-Fierros F, Teresa Barral M (2011) Interacting effect of $\mathrm{pH}$, phosphate and time on the release of arsenic from polluted river sediments (Anllns river, Spain). Aquat Geochem 17:281-306

Selim HM, Amacher MC, Iskandar IK (1989) Modeling the transport of chromium (vi) in soil columns. Soil Sci Soc Am J 53:996-1004

Shi Z, Di Toro DM, Allen HE, Ponizovsky AA (2005) Modeling kinetics of $\mathrm{Cu}$ and $\mathrm{Zn}$ release from soils. Environ Sci Technol 39:4562-4568

Smedley PL, Kinniburgh DG (2002) A review of the source, behaviour and distribution of arsenic in natural waters. Appl Geochem 17:517-568

Sparks DL (1989) Kinetics of soil chemical processes. Academic, San Diego

Teasdale PR, Apte SC, Ford PW, Batley GE, Koehnken L (2003) Geochemical cycling and speciation of copper in waters and sediments of Macquarie Harbour, Western Tasmania. Estuar Coast Shelf Sci 57:475-487
Van Herreweghe S, Swennen R, Vandecasteele C, Cappuyns V (2003) Solid phase speciation of arsenic by sequential extraction in standard reference materials and industrially contaminated soil samples. Environ Pollut 122:323-342

Varol M (2011) Assessment of heavy metal contamination in sediments of the Tigris River (Turkey) using pollution indices and multivariate statistical techniques. J Hazard Mater 195:355-364

Wang S, Mulligan CN (2006) Effect of natural organic matter on arsenic release from soils and sediments into groundwater. Environ Geochem Health 28:197-214

Wenzel WW, Kirchbaumer N, Prohaska T, Stingeder G, Lombi E, Adriano DC (2001) Arsenic fractionation in soils using an improved sequential extraction procedure. Anal Chim Acta 436:309-323

Wolkersdorfer C (2008) Water management at abandoned flooded underground mines. Springer, Heidelberg

World Health Organization (WHO) (1993) Guidelines for drinking water quality. Recommendations, 2nd edn. World Health Organization, Geneva

Yang JH, Zhou XH (2000) The Rb-Sr isochron of ore and pyrite subsamples from Linglong gold deposit, Jiaodong Peninsula, eastern China and their geological significance. Chin Sci Bull 45:22722277

Yin Y, Allen HE, Huang CP, Sparks DL, Sanders PF (1997) Kinetics of mercury(II) adsorption and desorption on soil. Environ Sci Technol 31:496-503

Zemberyova M, Bartekova J, Hagarova I (2006) The utilization of modified BCR three-step sequential extraction procedure for the fractionation of $\mathrm{Cd}, \mathrm{Cr}, \mathrm{Cu}, \mathrm{Ni}, \mathrm{Pb}$ and $\mathrm{Zn}$ in soil reference materials of different origins. Talanta 70:973-978

Zhang GS, Qu JH, Liu HJ, Liu RP, Li GT (2007) Removal mechanism of As(III) by a novel Fe-Mn binary oxide adsorbent: oxidation and sorption. Environ Sci Technol 41:4613-4619

Zhang H, Yu J, Zhou S (2014) Spatial distribution of As, Cr, Pb, Cd, Cu, and $\mathrm{Zn}$ in the water and sediment of a river impacted by gold mining. Mine Water Environ 33:206-216 